ЦОЙ Любовь Николаевна - кандидат социологических наук, руководитель исследовательского комитета «Социология конфликта» Российского общества социологов (117218, Россия, г. Москва, ул. Кржижановского, 24/35, корп. 5; tsoi-05@таil.ru)

\title{
СОЦИАЛЬНЫЕ ИННОВАЦИИ: РАЗРЕШЕНИЕ ИННОВАЦИОННЫХ КОНФЛИКТОВ
}

\begin{abstract}
Аннотация. В статье раскрывается конфликтологический аспект инновационной деятельности. Автор перечисляет основные атрибутивные свойства социальных инноваций, выделяет специфические особенности инноватора как конфликтогенного фактора, определяет понятийный статус конфликта и его психологизацию. В статье показывается содержательно-логическая связь между инновациями и конфликтами; раскрывается роль общественных стереотипов о конфликте, препятствующих развитию организации; вносятся различения между содержательными и коммунальными конфликтами. Автор перечисляет основные задачи, которые должен решать управленец в инновационной деятельности, и предлагает модель организационного конфликт-менеджмента как концепт управления инновационными конфликтами.
\end{abstract}

Ключевые слова: конфликтогенный фактор, психологизация конфликта, инновационная деятельность, инновационный конфликт, конфликтологическая компетентность, организационный конфликт-менеджмент

\section{Атрибутивные свойства социальных инноваций}

Управление инновационной деятельностью - это сфера разрешения инновационных и других конфликтов, достижение согласия между разными субъектами деятельности в целях развития организации.

Но для достижения такой цели требуются управленцы, специалисты и менеджеры, подготовленные к инновационной деятельности. У них должна быть сформирована конфликтологическая компетентность и культура разрешения конфликтов в организации. Говоря об инновациях во всех сферах деятельности, необходимо учитывать их сущностные характеристики и то, через какие феномены проявляются инновационные процессы. Социологи выявили основные характеристики социальных инноваций [Цой 1998]: это 1) высокий риск и высокая степень неопределенности; 2) актуализация противоречий и обострение конфликтов; 3) наличие сложно прогнозируемого побочного продукта (результата); 4) переход на новый уровень всей статусно-ролевой системы между участниками инновационного процесса.

Социальные инновации отличаются от технических инноваций тем, что последние разрабатывают новый продукт, не связанный напрямую с общественным сознанием. Продвижением нового продукта/товара занимаются маркетологи. А вот внедрение инноваций (идея, продукт, услуга и пр.) во многом зависит от коллектива, которому предстоит изменить свою деятельность, переучиваться, осваивать новые функции и т.д. Любое новшество вызывает сопротивление в коллективе, который раскалывается на три группы: инноваторов, консерваторов и «болото» - самую большую группу молчаливо протестующих. Между ними разворачиваются разные конфликты, часто коммунального характера. В случае если управленец не готов к конфликтам, заниматься инновационной деятельностью в любой сфере управления ему будет очень сложно. Он принесет больше вреда, чем пользы, и себе, и организации, и обществу.

Если мы возьмем сферу переподготовки, а точнее, подготовки к инновационной деятельности, образовательные технологии должны соответствовать требованиям к инновационной деятельности, т.е. необходимы инновационные технологии обучения [Дудченко 1996]. 
Такие технологии должны свести к минимуму или полностью устранить нерациональные затраты и непродуктивные потери времени, так или иначе связанные с образовательным процессом. Это такой режим обучения, при котором на единицу затраченных интеллектуальных усилий студент получает максимальный объем высококачественных и хорошо усвоенных знаний, т.к. сегодня следует оценивать систему образования, знания специалистов не по принципу «от достигнутого», который создает иллюзию ложного благополучия, а с учетом новых, беспредельно жестких требований к выживанию [Паранджанов 1997].

Будущие управленцы, которые непосредственно включаются в практику, должны четко осознавать, что их профессиональная деятельность непосредственно связана с инновациями и конфликтами. А это значит, что необходимо подготовить себя к такой ситуации, в которой возможно все, без чего, собственно, развитие не состоится.

Перечислим закономерные явления, сопровождающие любой конфликт, которые проявляются даже в том случае, если управленец действует идеально, не нарушая этических и других норм: это 1) угрозы; 2) психическое нападение с целью выбить из равновесия человека; 3) сплетни, слухи; 4) дезинформация, ложь; 5) подкуп; 6) стычки, негативная информация и т.п.

Как показывает опыт общения с большинством нынешних управленцев и руководителей, именно к этому они и не готовы. Конфликт начинает их разрушать, они испытывают в нем дискомфорт и стресс, разрушается коммуникация с теми, кто иначе смотрит на конфликт, хотя известно, что разные взгляды на конфликт как заложены самой природой конфликта, так и задаются рамками научных дисциплин, не говоря уже о практическом уровне интересов конфликтующих сторон. Таким образом, социальные инновации сопровождаются инновационными конфликтами.

\section{Инноваторы как конфликтогенный фактор}

В обществе всегда есть люди, которые рвутся вперед, в завтрашний день. Их не устраивает текущее положение дел, они выдвигают новые идеи, разрушая устои и прочные основы мироздания. Это новаторы, люди, которые реально создают переворот в обществе, производят трансформации и изменения, развивая и внедряя новшества.

Известно, что практически любое новшество ведет к малым или большим изменениям в обществе, оно вынуждает прощаться с привычным укладом жизни, а также связано с риском потери кем-либо спокойствия и преимуществ. Инноваторы - это, с одной стороны, опасные люди, т.к. часто всем недовольны, испытывают проблемы во взаимоотношениях с группой, конфликтны и неуживчивы. А с другой - без них многие процессы в производстве консервируются и не позволяют организации и обществу развиваться.

Инноватор - это центральная фигура всех преобразований в организации. Инноваторы являются конфликтогенным фактором, а потому отношение к ним неоднозначное, можно сказать, неравнодушное - от восхищения до ненависти, если реализация предлагаемых идей может, с одной стороны, сделать организацию мощной и конкурентоспособной, а с другой - поставить под угрозу спокойную жизнь коллектива. Инноватор не дает людям покоя и готов на многое ради воплощения идеи в жизнь.

Многие новые идеи воспринимаются как ересь, которая угрожает перевернуть привычный уклад жизни, а потому вызывает яростное сопротивление в организации и в обществе.

Необходимо отметить, что инноваторы наиболее уязвимы, поскольку, защи- 
щая идеи, они разрушают свое здоровье, теряют друзей, вносят сумятицу и раздражение, не дают спокойно жить ни себе ни другим.

Как защитить организацию от инноватора и инноватора от коллектива - это задача менеджеров, освоивших технологии конфликт-менеджмента в организации. Только понимая весь трагизм обновления, стагнации и развития, управленец/менеджер/руководитель может подготовить себя к сложным и мучительным процессам преобразования и инновационного развития.

\section{Понятийный статус конфликта}

Конфликтологический контекст развития организации задается только на основе фиксации проблем, и конструктивность здесь возможна в случае соотнесенности разных позиций, разнопредметных аспектов и актов фиксации проблем в организации. В этом случае под конфликтом имеется в виду разрыв целостности и столкновение разных позиций/функций в представлении о целостности деятельности организации.

Для организационного конфликт-менеджмента конфликт как проявление системных противоречий в поведении и коммуникации должен быть в центре внимания только наряду с изменением и потенциальным развитием в сопротивляющейся и агрессивной среде. Вне изменения, развития и решения проблем конфликт носит коммунальный характер, он психологизирован, а потому не может претендовать на понятийный статус.

Психологизация конфликта выдвигает на первый план яростную борьбу за выживание, за личные выгоды, за «правду и справедливость», за «моральные принципы и нравственность» несамоопределенного субъекта псевдоразвития. В этой ситуации на второй план (на обочину сознания) вытесняется ценность изменения/развития деятельности. Игнорируется процесс порождения «врагов», «рабов» или «зомбированных лиц», готовых на многое, чтобы развитие проходило без столкновений (без содержательного конфликта) взглядов, мнений, осознания ценностей тех субъектов, ради которых происходят изменение и развитие.

Поскольку переход «потенциального» в «актуальное» индивидуализирован, то возникающая межличностно-коммуникативная неравномерность соотношения «потенциального» и «актуального» в ситуации утраты/отсутствия полноты и целостности организации как деятельности приобретает форму «разрыва», или конфликта.

Управленческая проблема возникает именно в ситуации противоречия между актуальной фиксацией «потенциального» и возможностью актуализации «потенциального» в контексте развития как необходимости целенаправленного перехода «потенциального» в «актуальное». В случае отсутствия условий для перехода именно конфликт указывает на «разрывы» в деятельности организации и проблемы.

В ситуации развития и стратегических изменений главной задачей управленца является сохранение содержательного конфликта путем увеличения скорости соответствующей смены знаков, значений и смыслов «управленческого описания» ситуации развития, разрыва и конфликта, для чего необходима конфликтологическая аналитика.

\section{Общественные стереотипы о конфликте,}

\section{препятствующие развитию организации}

Негативное отношение к конфликту как к ситуации столкновения (конфликта) интересов, ценностей, мнений целей вполне устраивало советское общество, в котором для разрушительных конфликтов не было почвы. Советское общество 
развивалось по бесконфликтной модели, парткомы и профкомы знали, как разрешать конфликты в организациях или в семьях. Разрушение СССР и признание ценности демократии и рынка в российской конституции вынуждает признать столкновение (конфликты) разных интересов и борьбу за рынки, а также борьбу за власть и влияние на нее нормой. Поэтому разрушение сложившихся в советское время общественных стереотипов - это одна из задач конфликтологии.

В общественном сознании укоренилось отрицательное отношение к конфликту на основании следующих установок и мифов:

- конфликт вреден и опасен для человека, организации, государства и общества;

- конфликт - показатель плохой работы руководителя (менеджера);

- конфликтный человек опасен;

- в организации не должно быть конфликтов;

- от конфликта надо уходить и не обсуждать его в коллективе;

- конфликт разъединяет людей;

- конфликт - это стресс, в конфликте человек теряет здоровье и приобретает психосоматические заболевания;

- конфликт - показатель болезни организации;

- основной причиной конфликта в организации является плохое управление;

- причиной конфликтов являются личностные характеристики людей;

- конфликтный человек - это агрессивный человек;

- конфликт не бывает без насилия и агрессии;

- гармонические отношения несовместимы с конфликтными отношениями.

В общественном сознании при упоминании слова «конфликт» доминируют три образа.

1. «Пауки в банке», «кипяток», «ураган», «цунами», «неуправляемая стихия», «серпентарий» - такой образ конфликта ассоциируется с опасностью, разрушением, риском. Отношение к нему (конфликту) отрицательное, т.к. в нем нет хорошего, теряется здоровье, ухудшаются отношения с самыми близкими людьми, он ведет к потере работы и т.п.

2. Конфликт как средство, инструмент - «артподготовка перед боем», «экстрим» и как рациональный способ диагностики ситуации. В этом случае отношение к конфликту положительное, т.к. конфликт позволяет увидеть то, что ранее было невидимым, испытать коллектив на прочность, ясно отличать «своих» ОТ «чужих» и т.Д.

3. Конфликт - это стихия, которая разрушает («вулкан»). При выбросе вулканической смеси можно обнаружить крупицы драгоценных металлов и пустую породу. Но на месте разрушения возможна и новая жизнь. Часто такой образ формирует отношение к конфликту, которое зависит от личных потерь или приобретений: «если потеряю - плохое отношение», «если приобрету - хорошее».

Отрицательное отношение к конфликту является следствием тотального отождествления конфликта: 1) с насилием, 2) враждебностью, 3) агрессией, 4) негативными эмоциями, 5) разрушением.

Непрофессиональный взгляд на конфликт заключается в следовании вышеперечисленным стереотипам, в искажении сути конфликта, страхе перед ним, неспособности справиться с последствиями стрессов и нежелании (или неспособности) видеть в конфликте инновационный и конструктивный потенциал людей.

\section{Содержательные и коммунальные конфликты}

Коммунальные конфликты - это такой тип общения и коммуникации, который не связан с деятельностью организации. Содержанием коммунального 
общения является выяснение отношений, сплетни, слухи, самоутверждение через создание коммунальных конфликтов, переход на обсуждение личностных характеристик другого вне деятельности организации. Коммунальные провокации приводят к коммунальным конфликтам в организации.

Содержательная коммуникация связана только с профессионально-предметной деятельностью.

Для того чтобы строилась содержательная коммуникация, содержание общения в организации регулируется и ограничивается корпоративной культурой на принципах самоорганизации и самоконтроля. Но даже если мы имеем дело с содержательной коммуникацией, вовсе не факт, что здесь не будет почвы для возвращения в коммунальный слой общения. И для предотвращения этого необходимы определенные процедуры и мероприятия, способные снизить действие коммунальных конфликтов.

\section{Какие основные задачи должен решать управленец}

в инновационной деятельности?

1. Вывести конфликтующие стороны на новый уровень рефлексивного осмысления их места и роли в процессе развития организации.

2. Оказывать методическую, организационную, психологическую и иную помощь коллективу в поиске центра равновесия между изменением/развитием и стабильностью в организации.

3. Подготовить мышление инноваторов и консерваторов к изменениям в организации.

4. Создать условия для повышения квалификации/переобучения в области содержательно-конструктивного взаимодействия в коллективе, разрешения инновационных конфликтов.

5. Способствовать процессу деятельностного самоопределения коллектива в процессе развитии организации.

Таким образом, в случае если руководитель ставит задачу развития и внедрения инноваций в организации, то вопросы разрешения инновационных конфликтов, формирование конфликтологической компетенции должны занять достойное место в системе управления и повышения квалификации менеджеров и специалистов [Хасан 1996].

Минимизировать разрушительное влияние инновационных конфликтов на деятельность организации возможно путем повышения квалификации и формирования конфликтологической компетентности, освоения новых понятий по смыслу и содержанию.

Для организаций, внедряющих инновации и ставящих в центр внимания вопрос стратегического развития, предлагается современная модель управления инновационными конфликтами - организационный конфликт-менеджмент [Цой 2007].

\section{Организационный конфликт-менеджмент}

\section{как новая модель управления инновационными конфликтами}

Организационный конфликт-менеджмент - это не наука в строгом смысле слова, это технологическая дисциплина, ориентированная на практическую разработку технологий регулирования конфликтов в локальных конфликтных ситуациях, в процессах реализации инновационных проектов.

Организационный конфликт-менеджмент - это научно-практическое направление в рамках инновационного менеджмента. Как самостоятельный проект внутри организации, реализующей инновационные проекты, он представляет собой важный раздел инновационного менеджмента. 
В центре внимания организационного конфликт-менеджмента находятся четыре основополагающих процесса/понятия: инновации, конфликты (процессы сопротивления инновациям), риски и развитие. Функция организационного конфликт-менеджмента - сопровождение инноваций (инновационных проектов) в организации.

Как отдельная учебная дисциплина «Организационный конфликт-менеджмент» включает в себя четыре направления:

1) системные знания об инновациях, инновационном менеджменте, организации и о конфликтах;

2) технологию формирования конфликтологической компетентности;

3) развитие стрессо- и конфликтоустойчивости;

4) организационную культуру.

Организационный конфликт-менеджмент - это информационно-коммуникативная модель, которая органично объединяет две регулятивные технологии: технологию организации коммуникации между разными специалистами по поводу инноваций и технологию вмешательства/интервенции в конфликтные процессы с целью перевода конфликтного потенциала в нужное (для реализации инновации, для развития направления) русло [Глазл 2002].

Овладение конфликтом означает, что возможные разрушительные для организации последствия могут быть минимизированы, ограничены, но без прямого (насильственного) воздействия на процесс.

Посредством модели организационного конфликт-менеджмента есть возможность перевести коммунальный конфликт в содержательное русло, т.е. возможно заранее предотвратить развитие стихийного конфликта, взять его под контроль управления.

\section{Список литературы}

Глазл Ф. 2002. Конфликт-менеджмент. Настольная книга руководителя и консультанта (пер. с нем.). Калуга: Духовное познание. 516 с.

Дудченко В.С. 1996. Основы инновационной методологии. Институт социологии РАН. М.: На Воробьевых. 68 с.

Паранджанов В. 1997. Возможна ли новая революция в образовании? Образование будущего. - Высшее образование в России. № 2. С. 9-18.

Хасан Б.И. 1996. Психотехника и конфликтная компетентность. Красноярск: Фонд ментального здоровья. 157 с.

Цой Л.Н. 1998. Конфликт как существенная характеристика социальных инноваций. - Экстремальные ситуации, конфликты, согласие: сборник. М.: Академия управления МВД России, Институт социологии РАН. 100 с.

Цой Л.Н. 2007. Организационный конфликт-менеджмент: 111 вопросов, 111 ответов. М.: Книжный мир. 352 с.

\section{SOCIAL INNOVATION: THE INNOVATIVE RESOLUTION OF CONFLICTS}

Abstract. The article reveals the conflictological aspect of innovation. It lists the main attribute properties of social innovations, highlights specific features of the innovator as a conflictogenic factor, draws attention to the conceptual status of 
the conflict and its psychological character. The author shows content-logical connection between innovations and conflicts, reveals the role of social stereotypes about the conflict that hinder the development of the organization, and introduces the distinction between substantive and communal conflicts. The article considers the main tasks that a manager should solve in innovation activities and proposes the model of organizational conflict management as a concept of innovative conflict management.

Keywords: conflict-generating factors, psychologizing of conflict, innovative activity, innovative conflict, conflictological competence, organizational conflict management

\title{
УДК: 314/316
}

ДЕПЕЛЯН Рузанна Амбарцумовна - ассистент кафедры иностранных языков факультета государственного управления Московского государственного университета им. М.В. Ломоносова (119991, Россия, г. Москва, Ломоносовский пр-кm, 27, корn. 4; rdepelyan@mail.ru)

\section{ВИДЫ ИМИДЖА СОВРЕМЕННОЙ ОРГАНИЗАЦИИ}

\begin{abstract}
Аннотация. Предметом статьи является имидж организаций, а целью - разработка типологии видов имиджа организации и уточнение наименований и содержания видов имиджа организации. В статье автор показывает, что типологию видов имиджа организации целесообразно осуществлять по ряду оснований, таких как особенности и тип субъектов - носителей имиджа, наличие существования имиджевых свойств в организации, направленность общей оценки имиджа, меры удовлетворенности оценкой имиджа, возможность или невозможность фиксации восприятия имиджа и др.

Дальнейшие исследования имиджа организаций целесообразно сосредоточить на разработке практического инструментария, пригодного для осуществления диагностики имиджа и построения имидж-профилей организаций. Рекомендуемыми формами диагностики имиджа организаций являются разработка бланков вопросников для раздаточного или компьютерного анкетирования и тестирования участников организации, а также разработка сценариев интервью и гайдов для проведения фокус-групп.

Ключевые слова: типология имиджа организации, имидж вип-персон, имидж руководителей, имидж персонала, внешний имидж, внутренний имидж, актуальный имидж, потенциальный имидж, комплиментарный имидж, демонстрируемый имидж
\end{abstract}

$\mathrm{B}$ сфере исследования имиджа организации пока не сформирована общепризнанная типология видов имиджа, хотя исследования в этой области управления организациями разворачивались на протяжении всей второй половины XX в. Отчасти это связано с разнообразием компонентов, составляющих имидж организации, отчасти - с логикой развития исследований в сфере менеджмента организаций. Сравнительный анализ исследований имиджа организаций за последние 15 лет свидетельствует, что на данный момент существует множество точек зрения на виды имиджа организаций и их содержание. Имеет место некоторая терминологическая путаница понятий, а также приписывание одним и тем же понятиям разных смыслов. Особое беспокойство вызывает слабое различение внутреннего и внешнего имиджа организаций, что в ряде случаев влечет за собой некорректные и ошибочные выводы.

К проблеме разработки типологии видов имиджа организации, как правило, обращаются при проведении теоретических исследований либо в практическом менеджменте с целью диагностики, формирования или достижения более высокой результативности управления имиджем организации. Интересно, что в последние десятилетия этим вопросам посвящено немало практически ориентированных диссертационных исследований, выполненных российскими авторами [Рогалева 2007]. 